\title{
Experimental Study of Market Reputation Mechanisms
}

\author{
Kay-Yut Chen \\ Hewlett-Packard Labs \\ Kay-Yut.Chen@hp.com
}

\author{
Tad Hogg \\ Hewlett-Packard Labs \\ Tad.Hogg@hp.com
}

\author{
Nathan Wozny \\ California Institute of Technology
}

\begin{abstract}
We experimentally compare low-information, high-information and self-reporting reputation mechanisms. The results indicate players strategically reacted to the reputation mechanisms, with higher information mechanisms increasing market efficiency.
\end{abstract}

\section{Categories and Subject Descriptors}

J.4 [Computer Applications]: SOCIAL AND BEHAVIORAL SCIENCES

\section{General Terms}

Economics, Experimentation, Human Factors

\section{Keywords}

experimental economics, reputation, markets

\section{Reputation and Markets}

Reputations can help ensure promised actions are taken without the expense of external enforcement or third party monitoring [6]. The Internet and subsequent development of e-commerce allow an increasing number of small players to engage in buying and selling. However, this environment increases the importance of establishing trust in a market where everyone can choose to be anonymous. One approach is eBay's feedback mechanism in which participants rate the performance of the other party in their transactions.

Establishing trust is possible through repeated interactions, e.g., the tit-for-tat strategy in the iterated Prisoner's Dilemma [1]. The effects of various reputation mechanisms have been experimentally studied in simplified contexts. One approach [5] uses the "trust game" among pairs of players, where one player can choose to send money to a second, this amount is then substantially increased and the second player can choose to share some of that gain with the first player. By removing many of the complexities involved in market transactions, this game can study the effect of different policies of past behaviors revealed to participants. For questions involving reputation's effect on market efficiency, more complex experimental scenarios are needed. One example is a fixed-price market in which sellers have the option of not fulfilling their contracts [2]. Players are placed in pairs by the experimenter, and randomly assigned roles of buyer or seller. The buyer chooses whether to send the purchase price to the seller and, if so, the seller then decides whether to deliver the purchase or just keep the buyer's money. Revealing the seller's history of fulfillment then provides reputation information for the buyer. A similar one-sided market, but allowing variable prices, arises in an experimental study of a principal/agent market [4]. In this case the

Copyright is held by the author/owner(s).

EC'04, May 17-20, 2004, New York, New York, USA.

ACM 1-58113-711-0/04/0005. agents choose their level of service after principals have committed to their contracts. In this experiment, the agents face a market choice, maximizing the difference between their fee and expense on providing their service, but the payoff for the principal is probabilistic rather than directly determined by the choice made by the agent.

In the e-commerce context, although a given person may engage in many transactions, only a few may be with a particular person. In such cases, people face the question of whether a proposed transaction is likely to proceed as agreed. Moreover, unlike the Prisoner's Dilemma, people can choose not to do business with those deemed untrustworthy, or offer different terms based on the perceived level of trust. Furthermore, individuals usually cannot spread risk among many transactions, unlike large companies. This may lead to risk-averse people avoiding transactions that could benefit both parties, and thus result in lower market efficiency. Thus an important question is to what extent reputation mechanisms can aid this process. Analysis of eBay-like markets suggests that while feedback has desirable features in theory [3], such a market may not be efficient, fair and stable in practice.

To help address these issues, we designed experiments to provide a broader set of endogenous choices for the players than in the prior experimental work described above. First, the players can explicitly decide who they wish to do business with rather than being paired with a single other player by the experimenter. Thus we can examine whether people choose to use reputation information to ostracize those with low reputations or give them poor prices based on their higher perceived risk. Second, both buyers and sellers make fulfillment choices and so reputations are relevant to both sides of the market. In the context of self-reported information, this allows players the opportunity to choose to misreport their experience as possible punishment for a poor report on their own reputation. More generally, it allows for the formation of clusters of mutually high-reputation trading arrangements. Third, our experiments include a full market so prices and trading volumes are determined endogenously, providing a broader view of the macroeconomic consequences of different information policies than is possible in more restricted scenarios. On the other hand, the additional complexity of a full market and players selecting who to do business with makes for a more complicated theoretical analysis.

We choose to study reputation in the laboratory due to the uncontrollable nature of real world marketplaces. The key issues in designing reputation mechanisms are the nature of information to collect, its reliability and how it is disseminated to the participants. This paper reports on an experimental comparison of mechanisms revealing differing amounts of information on the transaction history of the players. We found that subjects 
responded to amount of information strategically. In addition, we observed the endogenously generated consequences for market price and volume.

\section{Experimental Design}

Laboratory economic experiments involve small groups interacting for only a few hours. Thus experiments with reputation mechanisms require a simple underlying market so participants can quickly build up enough transaction history to distinguish behaviors. Furthermore, the value of a high reputation decreases toward the end of an experiment, leading experienced subjects to not fulfill contracts. We thus need enough time to see at least some behavior relatively unaffected by this end-of-game effect.

The main component of the experiment is an exchange economy of a single homogenous good. Each unit of good a buyer purchased can be redeemed for a pre-determined amount of money. Each unit of good a seller sold costs a pre-determined amount of money. In each period, buyers and sellers receive tables listing their redemption values and costs, respectively. The aggregate supply and demand is kept constant across periods, and this is told to participants before each experiment. However, redemption values and costs were assigned to random individuals in each period.

We chose a discrete double auction as the market institution. Each period consists of a fixed number of rounds. Buyers and sellers took turns making offers and accepting offers made by others. Players were permitted to have only one offer at a time, although they may offer to buy or sell multiple units. In addition, we allowed the subjects to filter their offer, i.e., allowing only some agents to accept their offer. When an offer was accepted, it became a contract - an agreement for the seller to send the goods and for the buyer to send payment. The contracts were not binding. After the last round of exchanging offers, players were given a list of contracts they had accepted. They then decided whether or not to fulfill each contract. We included noise, as a fixed probability that either payments or goods are lost in transit. The information policy determines the past transaction behavior made available to participants. We used three information policies, announced at the start of each experiment:

1. Low information: Players knew only their own transactions.

2. High information: Players were told about all transactions that took place between any buyer and any seller.

3. Self-reported ratings: After contract fulfillment, players could give trading partners a positive or negative rating. A valueweighted score of the feedback is then made public.

Prior to the experiment, participants completed a short training program, with self-check quizzes, via the web (http://www.hpl.hp.com/econexperiment/MarketInfo/instructions.htm.)

\section{Results}

We conducted 8 experimental sessions. The first had 8 subjects. The rest had at least 12 subjects. In all experiments, market prices converged reasonably well to equilibrium within 3 periods. While rapid convergence is expected for the market [7], this may not have been the case with the our addition of non-binding contracts.
As expected, all experiments exhibit strong end-game effects. Subjects were told when the game would end two periods ahead of time. Fulfillment decreased sharply around 4 periods before the end of an experiment.

We expect people are more likely to fulfill contracts when more information about their actions is available to people deciding whether to transact future business with them. This matches our observation of lower fulfillment with the low information policy, where subjects can safely reason that only people with whom they had unfulfilled contracts know of their "bad" record. Thus, not fulfilling a contract is less costly to future business than the case with full information. This is also strong evidence that people react to strategic implications of how information is used by other people. The figure shows an example of our experimental results.

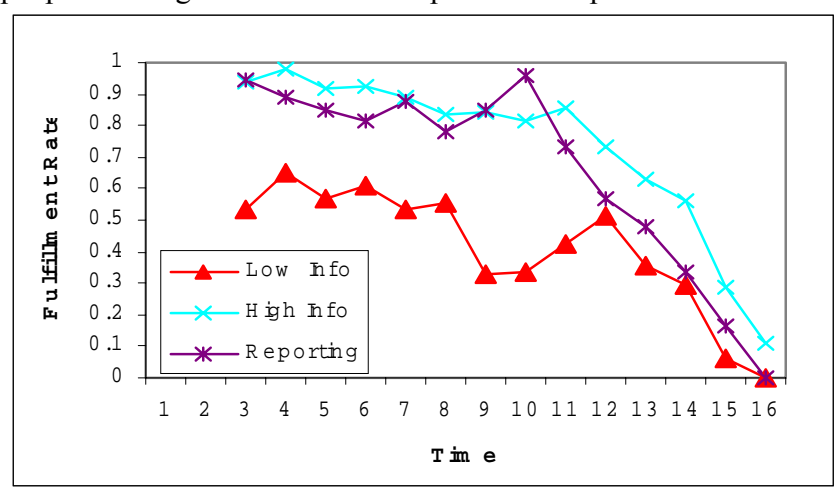

Fulfillment rates in the self-reporting treatment are similar to the high information treatment. This is consistent with observations on Internet auction sites such as eBay where the amount of negative feedback is only about $1 \%$. This is not direct evidence that cheating is rare since feedback does not have to be $100 \%$ accurate. Similarly, reports in our experiment were not always accurate. However, they were, on average, a good representation of how likely a subject is going to fulfill contracts.

Our experimental design allowed us to also observe endogenous macroeconomic effects: when fulfillment decreased, the contracted volume also increased but prices remained nearly constant. Market efficiencies responded to the level of fulfillment in a highly nonlinear fashion.

\section{References}

[1] R. Axelrod and W. Hampton, The Evolution of Cooperation, Science 211:1390-1396 (1981).

[2] G. Bolton et al., How Effective are Online Reputation Mechanisms?, Max Planck Institute paper 25-2002 (2002)

[3] C. Dellarocas, Analyzing the Economic Efficiency of eBaylike Online Reputation Mechanism, in Proc of $3^{\text {rd }}$ ACM Conf on E-Commerce, Oct 2001.

[4] D. DeJong, R. Forsythe and R. Lundholm, Ripoffs, Lemons and Reputation Formation in Agency Relationships: A Laboratory Market Study, Journal of Finance 40:809-823 (1985).

[5] C. Kesser, Experimental Games for the Design of Reputation Management Systems, IBM Systems J. 42:498 (2003).

[6] D. Klein, Reputation: Studies in the Voluntary Elicitation of Good Conduct, Univ. of Michigan Press 1997.

[7] V. Smith, Bargaining and Market Behavior: Essays in Experimental Economics, Cambridge Univ. Press, 2000. 